\title{
EDITORIAL
}

\section{The year of encroaching genomics}

The year 2000 has been called "The year of the genome". Perhaps better would have been to call it "The year of encroaching genomics" (Einarson and Golemis, 2000) intending by this vivid term the torrents of information pouring out of multiorganizational genome sequence projects, large research groups, consortia and industries into the field of active biological research.

This is bound to have a strong impact on how research strategies will be designed from now on and it is our expectation that the year 2001 will be the year in which the small academic laboratories now at the forefront of research will have to cope with this new situation if they are to remain at the cutting edge. They will have to show granting institutions how their new research project proposals involve collaboration with large scientific groups and industries such as those mentioned above in order to win financial backing.

Indeed, the last years of the past decade have already begun to see papers (e.g. Maleszka et al., 1998; Nadeau and Dunn, 1998) in which data gathered by the so-called classical in-situ methods were treated within a larger framework of comparative, evolutive or developmental analysis.

The access to this great amount of data appears to facilitate cloning, structural modelling to predict molecular functions, cross-genome comparisons and protein interaction approaches, which place otherwise uncharacterized open reading frames into specific pathways.

We hope that these prospects will inspire a new approach to research either at the level of cellular function (and therefore of the in situ localization and of the analytical interpretation of the data), or as a deeper probing into the physiological significance of the successions of facts involving the logical transfer of information from a gene or a class of genes to a functional genotypic transformation; or, still more importantly, in an applicative sense, to identify altered development or altered differentiation (cancerous).
The year 2001 thus promises to herald in a very innovative year in which programs will be introduced into our laboratories which will make it possible and necessary to use the vast stores of data coming from genomics and proteinomics.

But how can this sort o integration be achieved in practice?

In an article in the January 18, 2001 issue of Nature Insight, Endy and Brent give a glimpse of the future of a new style of research in cellular biology called "modelling cellular behaviour". They illustrate the possibility (and the necessity) of elaborating the enormous quantities of data available today by constructing models of cellular processes, obtained by incorporating knowable quantities of different entities, such as proteins, transcripts or regulatory sites, and the rates at which these entities, and the reactions among them, are governed by physical laws.

The article analyzes point by point qualitative an quantitative simulations and emphasizes the immenseness of the results that one can attain by delving deeply into these elaborations. The time is near when it will no longer be possible to do without such models constructed from large data bases. These will form the backbone of tools "to aid in optimization of existing biological systems and design new ones" and they will permit the "transfer of successful designs from models to life". In this way, the authors assert that such models can help reveal mechanisms into ways living systems regulate their temporal behaviour. Other biological systems can be described in terms of information processing. Finally, the use of models based on mechanisms found empirically may help to increase the capability of engineering living systems.

This particular situation of postgenomic biology ("postgenomic cultures") is even described in a short editorial of Nature, February 1, 2001 which comes back on the difficulties of research groups and institutions for embracing this new computational approach. 
However, for all of this work of elabortion to prove useful in offering us new insights that can readily be interpreted at the cellular level, it must, in our opinion, be compared with data from basic histochemical research according to the actual state of the technology as we know it today. We intend by this definition to mean the complex histochemistry of recent years, where qualitative and quantitative data (including flow cytometry), histoenzymological data, molecular biology data and electron microscopy data are integrated with the new refined microscopic systems.

I would like to note that this first number of volume 45 of the year 2001 opens with a series of papers dealing with some problems of plant cytochemistry. Interest in the world of plants has been a tradition of histochemistry since the time that Rothfelds (1966) and Rees (1972) published their pioneering papers. So the number 2 issue of the volume preceding this one (volume 44) has already been embellished with the beautiful review by Medina et al. on the "Functional organization of nucleolus in proliferating plant cells" which has been met with great success.

One of the areas of interest of the EJH, as stated in our program, is, in fact, "the cellular biology and the organization of tissues in animals and plants, as the basis for the study of function in normal and pathological conditions".

With this first issue of 2001 (see also the presentation by Carbonera et al., 2001) we would like to invite the botanists to actively collaborate, in order that the EJH may be also for them a forum for the comparison of recent ideas and innovations (methods and content) which constitutes the principal interest of research that animates this discipline.

M.G. Manfredi-Romanini

\section{REFERENCES}

Einarson M.B., and Golemis E.A.: Encroaching genomics: adapting large-scale science to small academic laboratories. Physiol. Genomics. 2, 185-92, 2000.

Carbonera D., Berta G., and Bonfante P.: Histochemistry for plant biology. Eur. J. Histochem. 45, , 2001

Endy D., and Brent R.: Modelling cellular behaviour. Nature 409, 391-395, 2001.
Maleszka R., de Couet H.G., and Miklos G.L.G.: Data transferibility from model organisms to human beings: insights from the functional genomics of the flightless region of Drosophila. Proc. Natl. Acad. Sci. U.S.A. 795- 373, 1998.

Nadeau J.H., and Dunn P.J.: Genomic strategies for defining and dissecting developmental and physiological pathways. Curr. Opin. Genet. Dev. 8, 311-315, 1998.

Postgenomic cultures. Editorial. Nature 409, 545, 2001.

Rothfels K., Sexsmith E., Heimburger M., and Krause M.O.: Chromosome size and DNA content of species of Anemone L. and related genera (Ranuncolaceae). Chromosoma 20, 54-74, 1966.

Rees H.: DNA in higher plants. In Evolution of genetic systems (eds. H.H. Smith) Gordon and Breach, New York, NY, 1972, pp. 394-418.

Medina F.J., Cerdido A., and de Càrcer G.: The functiona organization of the nucleolus in proliferating plant cells. Eur. J. Histochem. 44, 117-131, 2000. 


\section{HISTOCHEMISTRY FOR PLANT BIOLOGY}

The development and application of hystochemical, flow cytometric and hybridization techniques using radiolabeled and nonradioisotopic probes represent powerful tools for solving fundamental questions of plant molecular biology that inevitably require both qualitative and quantitative analysis of tissues, cell types or organelles as well as the localization ofgiven molecules and of their quantity. In the present issue five papers are presented to emphasize how the use of these techniques provided highlights in particular field of plant biology.

The two papers from Berta's group on the plantarbuscular mycorrhizal fungi (Lingua et al., 2001) and on plant-pathogen interaction (Lingua et al., 2001) represent a good example of this type of contribution. The first manuscript is mainly focused on the modifications induced by the arbuscular mycorrhizal colonization on the nucleus of root cortical cells. Nuclear hypertrophy observed in response to fungus invasion is related, as previously demonstrated by the same authors, to chromatin decondensation and to an increase in the ploidy level. Both the phenomena, i. e. the loosening of the chromatin structure and the increase of the DNA quantity, are involved in the control of the host gene expression.

Differently from the observations reported for the plant-arbuscular mycorrhizal (AM) fungi association, the plant-pathogen interaction seems to produce an opposite effect on the nuclear organization of root cells, leading to the block of endoreduplication. The interaction between Lycopersicon esculentum and two distinct pathogens, a phytoplasma of the stolbur group and the soil-borne fungus Phytophthora nicotiane var parasitica, has been investigated using light and electron microscopy as well as flow cytometry, thus allowing to demonstrate how pathogens are able to induce a lowering of the DNA quantity and chromatolysis or pyknosis in the root cell nuclei (Lingua et al., 2001).

The association between plants and mycorrhizal fungi is further discussed by Perotto's group (Bianciotto et al., 2001) analysing an intriguing aspect of such interaction: the possible role of AM fungi as a vehicle to spread plant growth-promot- ing rhizobacteria (PGRP) to neighbouring rhizospheres. Using confocal and electron microscopy, these authors demonstrated the involvement of extracellular polysaccharides of PGRP in the attachment of such bacteria to arbuscolar mycorrhizal structures, opening important perspectives in biotechnological applications.

In the last two papers presented in this issue the use of techniques for in situ localization has allowed to acquire information concerning two distinct topics. In the case of Carbonera's group (Balestrazzi et al., 2001) the spatial distribution of the transcripts derived from topl genes expression coding for the two isoforms ( $\alpha$ and $\beta$ ) of the enzyme DNA topoisomerase I was evaluated in Daucus carota. The elucidation of the expression pattern of a specific gene is in important factor in evaluating its physiological function. Authors approached this problem in two different systems related to cell proliferation: hypocotyls isolated and cultivated in the presence of the phytohormone 2,4$\mathrm{D}$ and somatic embryo populations, respectively. This study was performed by in situ hybridization, using radioactive specific probes. Moreover the specific localization of each topl transcript ( $\alpha$ and $\beta$ mRNA) was evaluated using hybridization techniques with gene-specific probes treated with a non-radioisotopic labeling system based on the use of digoxigenin. Both those techniques provided a useful aid to elucidate the role of topl genes during cell proliferation and differentiation events.

A comparison between two techniques allowing the localization of cellulose within the algal cell wall was performed by Baldan's group (Baldan $e t$ al., 2001). In this study of electron microscopy the use of periodic acid-thiosemicarbazide-silver proteinate (PATAg), an ultrastructural cytochemical test routinely adopted, was associated with the enzyme-gold labelling test that uses the cellulase enzyme complex as a cytochemical probe for the localization of cellulose. Authors, taking advantage of this new approach, acquired important information concerning the different composition of the cell wall in red, brown and green algae. 
We hope that this Issue providing papers on recent progress in particular areas of plant research could open the route to additional contribution in the field of Plant Biology.

Daniela Carbonera, University of Pavia Graziella Berta, University “A. Avogadro"

Paola Bonfante, University of Torino

\section{REFERENCES}

Baldan B., Andolfo P., Navazio L., Tolomio C., and Mariani P.: Cellulose in algal cell wall: an "in situ" localization. Eur. J. Histochem. 45, 2001.
Balestrazzi A., Bernacchia G., Pitto L., Luccarini G., and Carbonera C.: Spatial expression of DNA topoisomerase I genes during cell proliferation in Daucus carota. Eur. J. Histochem. $45, \ldots, 2001$

Bianciotto V., Andreotti S., Balestrini R., Bonfante P., and Perotto S.: Extracellular polysaccharides are involved in the attachment of Azospirillum brasilense and Rhizobium leguminosarum to arbuscular mycorrhizal structures. Eur. J. Histochem. 45 , 2001.

Lingua G., D’Agostino G., Fusconi A., and Berta G.: Nuclear changes in pathogen-infected tomato roots. Eur. J. Histochem. $45, \ldots ., 2001$.

Lingua G., Fusconi A., and Berta G.: The nucleus of differentiated root plant cells: modifications induced by arbuscular mycorrhizal fungi. Eur. J. Histochem. 45, ......, 2001. 